\section{Gametophytic Plants induced from Single Cells of Moss Callus}

Callus and callus-like tissues have been reported in a wide variety of plants. Steward et al. ${ }^{1}$ have described induced organization of intact plants from 'aggregates' which accumulated from single cells of carrot callus; Bristow $^{2}$ has reported induction of discrete fern plants (sporophytic and gametophytic) from his callus cultures under influence of growth substances, and Bauer ${ }^{3,4}$ has shown that varied sporophytic and gametophytic forms may be induced from callus of moss. This communication deals with aberrant moss plants, gametophytic in form, regularly induced from single-cell callus plantings of Polytrichum commune Hedw.

Diploid callus tissue of gametophytic origin (spore plantings) in this moss has been kept in culture with continuous proliferation through periodic transfers since its isolation ${ }^{5}$. No observable production of organized entities of either gametophytic or sporophytic character has occurred naturally in this period; the callus nature of the cellular aggregates has remained that of the original isolate when maintained on agar in vitro with media components favourable to growth of spores and normal moss gametophytes ${ }^{8}$.

Recently, organized plants of aberrant form and structure, having limited features of normal gametophytes, have been regularly induced from this callus on media containing growth substances.

Single, isolated cells of the callus (Fig. $1 D$ ), separated from the callus aggregates by agitation in sterile water, were planted to ensure exclusion of normal protonemata cells which might have accompanied the callus in the original transfers. The basic difference in size and initial division patterns of the callus cells and normal germinating spores in this species is shown in Fig. 1, $A-E$. Substrate for the single cells was media used for routine moss culture with additions of 1 p.p.m. naphthaleneacetic acid (NAA) and $\mathbf{0 . 2 5}$ per cent sucrose. Culture chambers were small Petri dishes sealed with polyethylene film. Glass micropipettes were used to transfer the single cells.

Isolated cells thus planted normally begin divisions within about four days (Fig. $1, D, E$ ), and the accumulation of an irregular cellular mass rapidly follows. Organized meristematic areas, portending the induced plants, appear at the periphery of the callus aggregate in about two or three weeks. Sections of the small cellular masses show an inner orientation and organization of cells long before emergence of the differentiated plants (Fig. 1G). Regularly 100 per cent of the cultures in a series of trials are successful, and numerous plants are cormmonly induced from the aggregate of a single cell culture.

The new gametophytic-appearing entities have definite organization, large, multicellular apical meristems and predictable patterns of division and differentiation, and they often bear rudimentary leaf-like appendages (Fig. $I F$ ). The initial growth is rapid, distinctly exceeding that of the callus aggregate on which they originated. Later (within 3-7 weeks) growth lessens in the absence of isolation and sub-culture, and the callus accumulations may gradually encompass the organized plants. The apical meristematic region of the plants under such conditions ordinarily begins to form callus.

Plants isolated and sub-cultured on media of the type which supported their initiation continue to grow, and limited branching is common (Fig. $I F$ ). Growth substance is clearly essential to both formation and maintenance of the organized plants, as also noted by Bristow in similar trials with fern callus ${ }^{2}$.

An obvious maturity and subsequent senility are evident in the transplants, whether transferred often or not. This manifestation occurs generally within three months after the original planting under growth conditions maintained for normal moss.

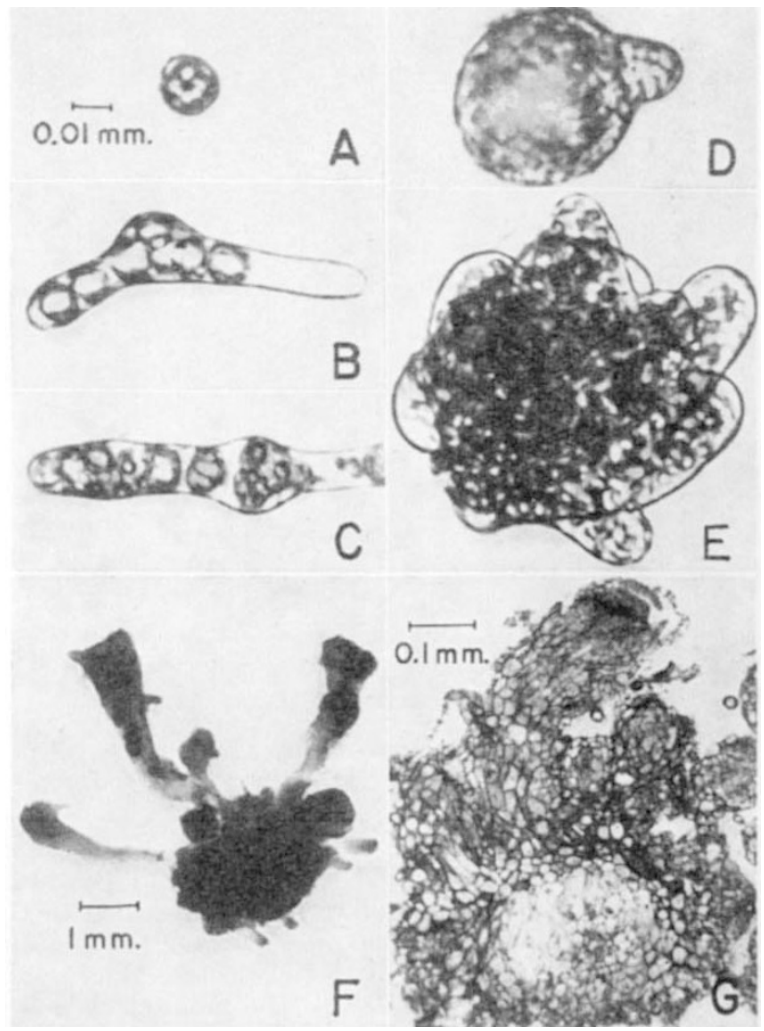

Fig. 1. $A, B, C$, ungerminated and germinating epores of Polytrichum commune, showing patterns of cell division and common orjentation of growth in two directions. $D, E$, single callus cell, undergoing first division, and several-celled callus aggregate resulting from typically random divisions (scale in $A$ is applicable to $A-E$ ). $F$, organized plant arising from callus aggregate within six weeks after callus was planted on medium containing 1 p.p.m. NAA. Ieaf-like appendages are at tip branches occur at sides. $G$, section of callus aggregate showing internal organization and (at top) detail of young meristematic tip of induced

Limited induction of these organized plant entities also results from use of other concentrations of NAA $(0 \cdot 1-$ 10 p.p.m.); 0.1-10 p.p.m. of indole-3-acetic acid; and 2,4-dichlorophenoxyacetic acid in concentrations of 1100 p.p.m. Gibberellic acid and indolebutyric acid have induced no responses.

The induced plants show essentially no sporophytic characteristics, as found in other mosses by Bauer ${ }^{3}$ or by $\mathrm{Lal}^{7}$ in certain other species, even though the callus in our experiments is determined to be diploid. The general aspect is that of a gametophyte, yet each new plant has a massive meristem and scale-like leaves (or none).

These aberrant plants are uniformly predictable; they can be induced with perfect regularity on appropriate media, and they arise either from single cell plantings on the initiating medium or from small aggregates of callus grown on the appropriate substrate. No special techniques are required to isolate the cells or to promote their subsequent growth.

This work was supported by grant $G-19369$ from the U.S. National Science Foundation. I thank Barbara Moore, Alvin Engelke and Sue Ellen Frederick for their assistance.

MAX WARD

Glenville State College,

Glenville, West Virginia.

'Steward, F. C., Mapes, M. O., Kent, A. E., and Holsten, R. D., Science, 143, 20 (1964).

- Bristow, J, Developmental Biol., 4, 361 (1962).

- Baver, L., Biolog. Zhl., 80, 353 (1961).

- Bauer, L., Ber. deutsch. bot. Gesell., 75, (11), 78 (1962).

- Ward, M., Science, 132, 1401 (1960).

- Ward, M., Bryologist, 63, 213 (1960).

' Lal, M., Phytomorph., 11, 263 (1961). 